\title{
Malocclusion prevalence and orthodontic treatment need in central Anatolian adolescents compared to European and other nations' adolescents
}

\author{
Fundagul Bilgic ${ }^{1}$, Ibrahim Erhan Gelgor², Ahmet Arif Celebi ${ }^{3}$
}

DOI: http://dx.doi.org/10.1590/2177-6709.20.6.075-081.oar

Objective: To determine the prevalence of malocclusion and orthodontic treatment need in a large sample of Central Anatolian adolescents and compare them with European-other nations' adolescents. Methods: The sample included 1125 boys and 1204 girls aged between 12 and 16 years with no previous orthodontic treatment history. Occlusal variables examined were molar relationship, overjet, overbite, crowding, midline diastema, posterior crossbite, and scissors bite. The dental health (DHC) and aesthetic components (AC) of the Index of Orthodontic Treatment Need (IOTN) were used as an assessment measure of the need for orthodontic treatment for the total sample. Results: The results indicated a high prevalence of Class I (34.9\%) and Class II, Division 1 malocclusions (40.0\%). Moreover, increased (18\%) and reduced bites (14.\%), and increased (25.1\%) and reversed overjet (10.\%) were present in the sample. Conclusion: Using the DHC of the IOTN, the proportion of subjects estimated to have great and very great treatment need (grades 4 and 5) was $28 . \%$. However, only $16.7 \%$ of individuals were in need (grades 8-10) of orthodontic treatment according to the AC.

Keywords: Malocclusion. Orthodontic treatment need. IOTN.

Objetivo: determinar a prevalência de má oclusão e a necessidade de tratamento ortodôntico em uma amostra extensa de adolescentes da Anatólia Central, e compará-los a adolescentes europeus de outras nacionalidades. Métodos: a amostra consistiu de 1125 meninos e 1204 meninas, com idades entre 12 e 16 anos, sem histórico de tratamento ortodôntico prévio. As variáveis oclusais avaliadas foram a relação entre molares, overjet, overbite, apinhamento, diastema na linha média, mordida cruzada posterior e mordida em tesoura. O Componente de Saúde Dental (DHC) e o Componente Estético (AC) do Índice de Necessidade de Tratamento Ortodôntico (IOTN) foram utilizados para avaliar a necessidade de tratamento ortodôntico de toda a amostra. Resultados: os resultados sugerem uma alta prevalência de má oclusão de Classe I $(34,9 \%)$ e Classe II, subdivisão 1 (40,0\%). Além disso, overbite aumentado $(18,3 \%)$ e reduzido (14,4\%), e overjet aumentado $(25,1 \%)$ e reduzido $(10,4 \%)$ também foram observados na amostra. Conclusão: com base no uso do DHC do IOTN, observou-se que a proporção dos indivíduos avaliados com necessidade grande e muito grande de tratamento (notas 4 e 5 ) foi de $28,7 \%$. Porém, de acordo com o AC, apenas 16,7\% dos indivíduos apresentaram necessidade (notas 8-10) de tratamento ortodôntico.

Palavras-chave: Má oclusão. Necessidade de tratamento ortodôntico. IOTN.

${ }^{1}$ Assistant Professor, Mustafa Kemal University, Faculty of Dentistry, Department of Orthodontics, Hatay, Turkey.

${ }^{2}$ Professor, Kirikkale University, Faculty of Dentistry, Department of Orthodontics, Kirikkale, Turkey.

${ }^{3}$ Lecturer, Ishik University, Faculty of Dentistry, Department of Orthodontics, Erbil, Iraq.

\author{
How to cite this article: Bilgic F, Gelgor IE, Celebi AA. Malocclusion preva- \\ lence and orthodontic treatment need in central Anatolian adolescents compared \\ to European and other nations' adolescents. Dental Press J Orthod. 2015 Nov- \\ Dec;20(6):75-81. DOI: http://dx.doi.org/10.1590/2177-6709.20.6.075-081.oar \\ Submitted: February 04, 2015 - Revised and accepted: July 06, 2015 \\ » The authors report no commercial, proprietary or financial interest in the products \\ or companies described in this article. \\ Contact address: Fundagul Bilgic \\ Email: fundagulbilgic@hotmail.com
}




\section{INTRODUCTION}

On an increased basis, malocclusion is considered an expression of normal biologic variation, and treatment need is often based as much on psychosocial concerns as on proven oral health risks attributable to malocclusion. ${ }^{1}$ The criteria for determining who is most likely to benefit from orthodontic treatment are controversial. These factors make it particularly difficult for the general dentist to determine for whom orthodontic treatment is clearly indicated, since the traditional pathway to orthodontic care starts at the general dentist's office.

Different populations have been investigated to provide epidemiological data of the prevalence of malocclusion..$^{2-7}$ As a common trend, quantitative variables along with Angle's classification were used in these reports. Additionally, treatment-need indexes were also used to determine orthodontic need based on esthetic impairment, potential for adverse effect on dental health, and deviation from normal occlusion. ${ }^{8}$ The Index of Orthodontic Treatment Need (IOTN), involving the Dental Health Component (DHC) and the Aesthetic Component (AC), is the tool most frequently used for measuring treatment need., ${ }^{910}$ Perhaps, being objective and synthetic, and allowing for comparisons between different population groups, are the most important aspects of this index. 7,11,12

Certain European populations, such as the Swedish, ${ }^{13}$ British, ${ }^{14}$ German, ${ }^{5,15}$ French $^{16}$ and Italian ${ }^{6,7,17}$ have been examined extensively in regards to IOTN. However, there is little research and/or published data that evaluated together the prevalence of malocclu$\operatorname{sion}^{8,18}$ and orthodontic treatment need ${ }^{19,20}$ in adolescents. Therefore, the aim of the present survey was to document the prevalence of individual traits of malocclusion, and to assess the need for orthodontic treatment in relation to sex by using the IOTN in a group of adolescent schoolchildren. It also aimed to compare the data provided with the findings of chiefly European patients as well as other surveys.

\section{MATERIAL AND METHODS}

Data were collected during an epidemiological survey, in the period of May, 2008 to December, 2012, from 2329 adolescents (1125 males and 1204 females) aged 12.5-16.2 years, randomly selected using a onestage cluster sampling procedure in 13 state-funded secondary schools in Kirikale city which is located in the south area of the capital of Turkey. The schools were randomly selected from an initial pool of 27 schools that had been previously identified by the school district to avoid possible biases ensuing from social heterogeneity. Written parent informed consent forms were obtained for dental examinations. Family origin and registration information were examined in order to determine that the sample was a good representative of ancestry from the central part of the country. All male and female patients who met the following criteria were included in the sample: (1) age from 12 to 16 years; (2) secondary dentition present with no remaining deciduous teeth; (3) no multiple missing teeth; (4) presence of first permanent canines and molars; and (5) no previous history of orthodontic treatment. Each examination took place while the subject was seated in a standard, quiet classroom in the designated chairs. Clinical examination was carried out by one examiner who was previously calibrated. The examination lasted 20 minutes per child, following the World Health Organization guidelines. ${ }^{21}$

\section{Orthodontic variables}

Patients with an occlusal pattern that deviated from the ideal Class I relationship, which is based on the buccal groove of the mandibular first molar settled on the mesiobuccal cusp of the maxillary first molar as described by Angle, (including crowding, spacing, rotations), were categorized as Class I malocclusion. Thus, the Class I normal category was limited to patients with occlusions that were ideal or near ideal. Patients with a different Angle classification of occlusion on each side were categorized into a single Class based on the predominant pattern of occlusion and/or canine relationship., ${ }^{4,22}$

For overbite and overjet, values between 0 and $4 \mathrm{~mm}$ were considered normal. ${ }^{7}$ Posterior crossbite and scissors bite were registered as bilateral, right and left. ${ }^{4,5}$ Crowding was recorded for the incisor and also posterior segments of each jaw $(1-3 \mathrm{~mm}=$ mild; 4-6 $\mathrm{mm}=$ moderate; $>6 \mathrm{~mm}=$ severe $).{ }^{4}$ Anterior diastema was diagnosed when there was a space of at least $1 \mathrm{~mm}$ between central incisors in either arch. ${ }^{4}$

Patients with a normal occlusion pattern had normal molar and canine relationships, no crowding or crossbites, normal overjet and overbite, well-balanced faces, and no history of previous orthodontic treatment. 


\section{Orthodontic treatment need}

The findings served to determine orthodontic treatment need with reference to the IOTN ${ }^{9,10}$ which consists of the DHC and the AC. Considerations as to no treatment need, borderline need, or great need were based on five grades in the DHC and 10 grades in the AC.

\section{Statistical analysis}

To test examiner reproducibility, 25 children were reexamined by Kappa's method four weeks after initial examination..$^{23}$ The ratio of the sample, as a maximum estimate of the proportion of individual traits of malocclusion in the whole population, was calculated for the total sample and for girls and boys separately. The number of subjects with diagnosed anomaly (n) and its prevalence (n/N x 100, in which $\mathrm{N}$ is the number of subjects examined) was determined. The differences between sex groups were assessed by means of chi-square test. Data were analyzed by SPSS software package (version 21.0, SPSS Inc., Chicago, Ill., USA). for IOTN DHC and AC grades. Level of significance was established at $p<0.05$.

\section{RESULTS}

Kappa test indicated high reliability and reproducibility $(0.73-0.80)$ for the parameters tested. Table 1 presents the prevalence of each occlusal trait in the total sample. Class I malocclusion was found in 812 subjects, which represented 34.9\% of the 2329 individuals examined. Class II malocclusion was diagnosed in 1041 individuals, $40.0 \%$ of all patients were Division 1 and $4.7 \%$ of all patients were Division 2. Class III malocclusion was found in 240 subjects, $10.3 \%$ of the sample. Normal overbite was the most common (73.5\%), mostly observed in girls $(p<0.001)$. Increased overbite was recorded in $18.3 \%$ of the sample, mostly observed in boys $(p<0.05)$. The prevalence of reduced bite value was found as $8.2 \%$. Normal overjet was present in 1371 individuals (64.5\%). Prevalence of increased overjet (25.1\%) was found to be higher than negative overjet (10.4\%). While crossbite was found more frequently, as much as of $4.0 \%$ of the sample, scissors bite was rarely diagnosed in only $0.3 \%$ of the subjects.

Anterior crowding was present in 1638 individuals (66.2\%) (Table 2); 17.9, 9.1 and 38.1\% of those had crowding in the upper arch, lower arch and both arches, respectively. Moderate crowding was more common in both arches. Midline and spread diastemas were found in 14.8 and $12.9 \%$ of the sample, respectively. Diastemas were observed mostly in the upper $\operatorname{arch}($ Table 2).

In the study group, the IOTN revealed no treatment need in $45.6 \%$ of the sample, when the DHC was used (mostly in boys $(p<0.05)$ and $43.1 \%$ when the AC was used. (Figs 1 and 2, and Tables 3 and 4). When borderline cases were taken into consideration, treatment need was diagnosed in $25.7 \%$ of the sample when the DHC was used and in 40.2\% when the AC was used. The number of subjects with the need for orthodontic treatment was 648 (28.7\%) when the DHC was used, and $376(16.7 \%)$ when the AC was used.

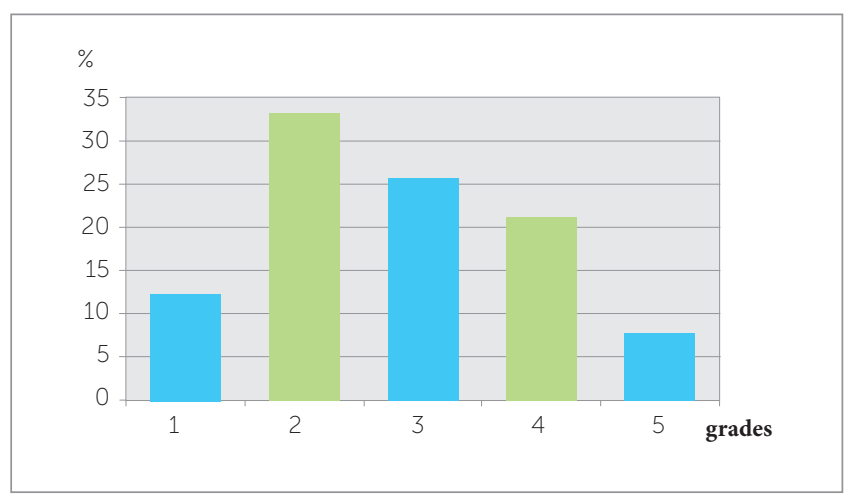

Figure 1 - Dental Health Component (DHC) grades of the Index of Orthodontic Treatment Need (IOTN) in Anatolian adolescents (Grades 1 and 2, no need; Grade 3, borderline need; Grades 4 and 5, definite need).

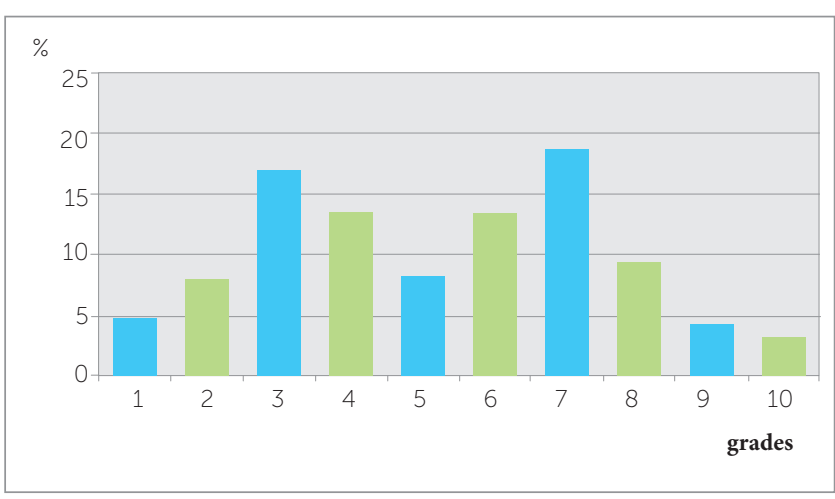

Figure 2 - Aesthetic component (AC) grades of the Index of Orthodontic Treatment Need (IOTN) in Anatolian adolescents (Grades 1-4, no need; Grade 5-7, borderline need; Grades 8-10, definite need). 
Table 1 - Occlusal classifications

\begin{tabular}{|c|c|c|c|c|c|c|c|c|c|c|}
\hline & & & \multicolumn{2}{|c|}{ Boys } & \multicolumn{2}{|c|}{ Girls } & \multicolumn{2}{|c|}{ Total } & \multirow{2}{*}{\multicolumn{2}{|c|}{$p$-value }} \\
\hline & & & $\mathbf{n}$ & $\%$ & $\mathbf{n}$ & $\%$ & $\mathbf{n}$ & $\%$ & & \\
\hline \multicolumn{11}{|c|}{ Occlusal anteroposterior relationships } \\
\hline Normal occlusion & & & 110 & 9.8 & 126 & 10.5 & 236 & 10.1 & NS & 0.63 \\
\hline Class I & & & 404 & 35.9 & 408 & 33.9 & 812 & 34.9 & NS & 0.317 \\
\hline Class II, Division 1 & & & 448 & 39.8 & 483 & 40.1 & 931 & 40.0 & NS & 0.899 \\
\hline Class II, Division 2 & & & 56 & 5.0 & 54 & 4.5 & 110 & 4.7 & NS & 0.625 \\
\hline Class III & & & 107 & 9.5 & 133 & 11.0 & 240 & 10.3 & NS & 0.246 \\
\hline \multicolumn{11}{|c|}{ Distribution of overbite } \\
\hline Normal (0-4 mm) & & & 802 & 71.2 & 913 & 75.8 & 1715 & 73.5 & $\star \star \star \star$ & 0.0001 \\
\hline Increased (> $4 \mathrm{~mm}$ ) & & & 227 & 20.2 & 197 & 16.4 & 424 & 18.3 & * & 0.018 \\
\hline Reduced $(<0 \mathrm{~mm})$ & & & 96 & 8.5 & 94 & 7.8 & 190 & 8.2 & NS & 0.098 \\
\hline \multicolumn{11}{|c|}{ Distribution of overjet } \\
\hline Normal & & & 731 & 65 & 770 & 64 & 1501 & 64.5 & NS & 0.866 \\
\hline Increased & & & 281 & 25 & 304 & 25.2 & 585 & 25.1 & NS & 0.886 \\
\hline Negative & & & 113 & 10 & 130 & 10.8 & 243 & 10.4 & NS & 0.588 \\
\hline \multicolumn{11}{|c|}{ Distribution of posterior crossbite and scissors bite } \\
\hline \multirow{4}{*}{ Crossbite } & No finding & & 1021 & 90.8 & 1082 & 89.9 & 2103 & 90.3 & NS & 0.677 \\
\hline & Bilateral & & 41 & 3.6 & 52 & 4.3 & 93 & 4.0 & NS & 0.544 \\
\hline & Unilateral & right & 35 & 3.1 & 41 & 3.4 & 76 & 3.3 & NS & 0.890 \\
\hline & & left & 24 & 2.1 & 27 & 2.2 & 51 & 2.2 & NS & 0.970 \\
\hline \multirow{3}{*}{ Scissors bite } & Bilateral & & 1 & 0.1 & 1 & 0.1 & 2 & 0.1 & NS & 0.957 \\
\hline & Unilateral & right & 2 & 0.2 & 0 & 0.0 & 2 & 0.1 & NS & 0.949 \\
\hline & & left & 1 & 0.1 & 1 & 0.1 & 2 & 0.1 & NS & 0.889 \\
\hline
\end{tabular}

NS: Not significant. ${ }^{*} p<0.05 ;{ }^{* *} p<0.001$.

Table 2 - Distribution of crowding and diastema.

\begin{tabular}{|c|c|c|c|c|c|c|c|c|c|}
\hline & & \multicolumn{2}{|c|}{ Boys } & \multicolumn{2}{|c|}{ Girls } & \multicolumn{2}{|c|}{ Total } & \multirow{2}{*}{\multicolumn{2}{|c|}{$p$}} \\
\hline & & $n$ & $\%$ & $\mathbf{n}$ & $\%$ & n & $\%$ & & \\
\hline \multicolumn{10}{|c|}{ Crowding } \\
\hline No crowding & & 383 & 34.0 & 428 & 35.5 & 811 & 34.8 & NS & 0.460 \\
\hline \multirow{3}{*}{$\begin{array}{l}\text { Upper arch, } \\
\text { only }\end{array}$} & mild & 140 & 12.4 & 120 & 10.0 & 260 & 11.2 & NS & 0.214 \\
\hline & moderate & 55 & 4.9 & 60 & 5.0 & 115 & 4.9 & NS & 0.732 \\
\hline & severe & 18 & 1.6 & 24 & 2.0 & 42 & 1.8 & NS & 0.810 \\
\hline \multirow{3}{*}{$\begin{array}{l}\text { Lower arch, } \\
\text { only }\end{array}$} & mild & 67 & 6.0 & 70 & 5.8 & 137 & 5.9 & NS & 0.845 \\
\hline & moderate & 28 & 2.5 & 31 & 2.6 & 59 & 2.5 & NS & 0.760 \\
\hline & severe & 8 & 0.7 & 9 & 0.7 & 17 & 0.7 & NS & 0.77 \\
\hline \multirow{3}{*}{ Both arches } & mild & 280 & 24.9 & 303 & 25.2 & 583 & 25.0 & NS & 0.981 \\
\hline & moderate & 127 & 11.3 & 137 & 11.4 & 264 & 11.3 & NS & 0.831 \\
\hline & severe & 19 & 1.7 & 22 & 1.8 & 41 & 1.8 & NS & 0.985 \\
\hline \multicolumn{10}{|c|}{ Diastema } \\
\hline No finding & & 808 & 71.8 & 852 & 70.8 & 1660 & 71.3 & NS & 0.328 \\
\hline \multirow{2}{*}{ Upper arch } & midline & 140 & 12.4 & 156 & 13 & 296 & 12.7 & NS & 0.214 \\
\hline & spread & 99 & 8.8 & 95 & 7.9 & 194 & 8.4 & NS & 0.632 \\
\hline \multirow{2}{*}{ Lower arch } & midline & 20 & 1.8 & 30 & 2.4 & 50 & 2.1 & NS & 0.870 \\
\hline & spread & 58 & 5.2 & 71 & 5.9 & 129 & 5.5 & NS & 0.670 \\
\hline
\end{tabular}

NS: Not significant 
Table 3 - DHC of IOTN statistics of boys and girls

\begin{tabular}{|c|c|c|c|c|c|c|c|c|}
\hline \multirow{2}{*}{$\begin{array}{l}\text { Occlusal } \\
\text { anteroposterior } \\
\text { relations-hips }\end{array}$} & \multicolumn{2}{|c|}{ Boys } & \multicolumn{2}{|c|}{ Cirls } & \multicolumn{2}{|c|}{ Total } & & \multirow[t]{2}{*}{ p-value } \\
\hline & $n$ & $\%$ & n & $\%$ & $n$ & $\%$ & & \\
\hline No need & 531 & 48.3 & 492 & 42.8 & 1023 & 45.6 & * & 0.01 \\
\hline Borderline need & 263 & 23.9 & 316 & 27.5 & 579 & 25.7 & NS & 0.054 \\
\hline Need & 306 & 27.8 & 342 & 29.7 & 648 & 28.7 & NS & 0.328 \\
\hline Total & 1100 & 100 & 1150 & 100 & 2250 & 100 & & \\
\hline
\end{tabular}

*,p < 0.05; NS: Not significant.

Table 4 - AC of IOTN statistics of boys and girls

\begin{tabular}{|c|c|c|c|c|c|c|c|c|}
\hline \multirow{2}{*}{$\begin{array}{l}\text { Occlusal } \\
\text { anteroposterior } \\
\text { relationships }\end{array}$} & \multicolumn{2}{|c|}{ Boys } & \multicolumn{2}{|c|}{ Girls } & \multicolumn{2}{|c|}{ Total } & & \multirow[t]{2}{*}{$p$-value } \\
\hline & n & $\%$ & $n$ & $\%$ & $n$ & $\%$ & & \\
\hline No need & 492 & 44.6 & 478 & 41.6 & 970 & 43.1 & NS & 0.136 \\
\hline Borderline need & 437 & 39.6 & 467 & 40.7 & 904 & 40.2 & NS & 0.699 \\
\hline Need & 171 & 15.4 & 205 & 17.9 & 376 & 16.7 & NS & 0.142 \\
\hline Total & 1100 & 100 & 1150 & 100 & 2250 & 100 & & \\
\hline
\end{tabular}

NS: Not significant.

\section{DISCUSSION}

Although many studies were published to describe the prevalence and types of malocclusion, when examining a certain population it is difficult to compare and contrast these findings, partly because of the varying methods and indexes used to assess and record occlusal relationships, age differences of the study populations, examiner subjectivity, specific objectives, and differing sample sizes. ${ }^{22}$ Methodology used in this study was mostly collected from European studies, $4,6,7,22$ and our results were discussed with the findings from different European geological regions due to close proximity and since there was limited information of individuals in the literature. The general consensus about treatment timing for malocclusions is that it should start around permanent dentition. At this stage, maxillary and mandibular development is almost completed and the malocclusion takes its final pattern. Given the characteristics of the sample, this paper demonstrated the occlusal traits of an untreated adolescent population at those ages.

With respect to the occlusal findings, Class I malocclusion was found in $34.9 \%$ of the sample. This Class I occlusion figure included individuals with incisor crowding and dental malalignment and thus did not imply ideal normal occlusion. The prevalence of Class II, Division 1 (40.0\%), in the present study, was greater than the rates reported for English school children (12.5\%), ${ }^{24}$ Shropshire school population (27.2\%), ${ }^{25}$ adolescents in Bogotá (14.9\%), ${ }^{4}$ and Italian school adolescents $\left(36.3 \%\right.$. $^{7}$ However, Lauc ${ }^{26}$ on Hvar Island, and Josefsson et $\mathrm{a}^{13}$ for a Swedish population, found that Class II malocclusion was more common in their population (greater than 45\%), and explained this figure by a genetic influence on the incidence of Class II malocclusions. Early treatment in the primary or early mixed dentition has been recommended for Class III malocclusions., ${ }^{47}$ The prevalence of Class III malocclusion determined in this study is $10.3 \%$. However, Goose et $\mathrm{al}^{28}(2.91 \%)$, Haynes ${ }^{24}(2.5 \%)$, Foster and $\operatorname{Day}^{25}(3.5 \%)$, Proffit et $\mathrm{al}^{29}(5.7 \%)$, Thilander et $\mathrm{al}^{4}$ (5.8\%), Lauc $^{26}$ (4.8\%), and Perillo et al ${ }^{7}$ (4.3\%) reported lower rates. The present study confirmed that the predominant anteroposterior relationship of the arches in adolescents was Class II, Division 1. Of the vertical anomalies, increased overbite was more than twice as frequent as anterior open bite. Our results were similar to the rates reported by Thilander et $\mathrm{al}^{4}$ and $\mathrm{Lauc}^{26}$ who 
also claimed that deep bite was often associated with a Class II malocclusion and more common in boys. However, higher ratios were found in Italian samples. ${ }^{6,7}$ Increased overjet proved to be as high as increased overbite in this study; this is a reflection of the higher prevalence of Class II malocclusion among adolescents. Our findings agree with those of Thilander et al, ${ }^{4}$ in Bogotanian adolescents, and Ciuffolo et al, ${ }^{6}$ in Italian adolescents, in which high rates of increased overjet in the permanent dentition were reported. In a French sample, increased overjet was present in fewer subjects $(6 \%){ }^{3}$

In this study, uni/bilateral posterior crossbite was more frequent than scissors bite and was observed in $9.5 \%$ of the sample. This rate was similar to the findings of Ciuffolo et $\mathrm{al}^{6}$ and higher than Thilander et al. ${ }^{4}$ Perillo et $\mathrm{al}^{7}$ showed a higher percentage for crossbite and scissors bite (14.2 and 3.5\%, respectively).

Crowding, in one or both arches, was the most frequent of all anomalies recorded (66.2\%). This finding complied with the results of Thilander et $\mathrm{al}^{4}$ and Lauc. ${ }^{26}$ There is a general consensus that treatment of crowding should start in the permanent dentition. ${ }^{5}$ The National Health and Nutrition Survey III, undertaken in the United States between 1989 and 1994, showed a frequency of crowding ranging from 42.3\% at ages $8-11$ to $54.5 \%$ at ages $12-17$, which was lower than the frequencies observed in this investigation. ${ }^{29}$ Nevertheless, other studies have reported lower rates of crowding located in anterior/both segments. 3,6,7,24,25

Thilander et $\mathrm{al}^{4}$ found the prevalence of median diastema in their population to be $13.5 \%$ in the early mixed and $4 \%$ in the permanent dentition. Lauc ${ }^{26} \mathrm{ob}-$ served a high rate of midline diastema (45.1\%). In contrast, in our study, this rate was $12.7 \%$. Perillo et $\mathrm{al}^{7}$ showed the prevalence of median diastema as equal to 9.9\%. The frequency of diastema in Nigeria was 24\%. ${ }^{30}$

Administrators of publicly funded programs need a valid screening method to determine priority for orthodontic treatment. ${ }^{15}$ Priority of orthodontic care through national health care plans in European countries has been a prime factor behind the development of indexes, such as the IOTN.

The need for orthodontic treatment has been presented in the literature by means of different indexes. In the present study, the classification by the IOTN was used because the authors' are familiar with this index.
In Turkey, there are few epidemiologic surveys. Guray et $\mathrm{l}^{19}$ used the Treatment Priority Index (TPI) and found that $72.26 \%$ of 483 students required orthodontic treatment in a primary school with a low socioeconomic standard from Konya district (South Anatolia). Ugur et $\mathrm{al}^{20}$ found a $37.77 \%$ orthodontic treatment need, by using the TPI in 5726 to 10-year-old Turkish primary school children with a high socioeconomic standard in central Anatolia. Our study was carried out in a large adolescent sample with moderate socioeconomic status, and treatment need was lower than those two studies. These studies conducted in different regions show similar results in terms of the need for orthodontic treatment in individuals with different socio-cultural features in different locations. The results of this study were not in agreement with Ugur et $\mathrm{al}^{20}$ who determined that orthodontic treatment needs increase with age. In our study, according to the DHC of the IOTN, 28.7\% of the whole sample was classified as being in need of orthodontic treatment (grades 4 and 5). The results showed that the percentage was relatively greater than those reported by Souames et $\mathrm{al}^{16}$ in France and Perillo et $\mathrm{al}^{7}$ in Italy (21.3 and 27.3\%, respectively). However, the British studies found a higher prevalence rate for untreated subjects: $32.7 \%,{ }^{10} 33 \%$ and, $35 \% .{ }^{14}$ Josefsson et $\mathrm{al}^{13}$ found $39.5 \%$ of orthodontic treatment need in a Swedish sample. The findings of the present study, therefore, indicated that a substantial need for orthodontic intervention was present at a similar level to French and Italian children, but generally lower than northern European populations (United Kingdom and Sweden).

The AC for IOTN, in the present study, reduced orthodontic treatment need (16.7\%). This has also been reported in other studies. ${ }^{10,13,16}$ Tausche et $\mathrm{al}^{5}$ claimed that the AC alone failed to identify any children needing orthodontic treatment. Because of the AC alone is an inappropriate method for screening treatment need, lack of agreement occurs between the normative component and the IOTN-AC. However, Josefsson et $\mathrm{a}^{13}$ used the AC both by the examiner and the subject. This study also hunted up a difference between males and females for orthodontic treatment need. Treatment need did not differ significantly as a result of sex. AC alone is unsuitable for screening treatment need. 


\section{CONCLUSION}

The results of this investigation demonstrated that Class II, Division 1 malocclusion was the most prevalent occlusal pattern among adolescents, and the high incidence of increased overjet and overbite are a reflection of the high prevalence of Class II malocclusion. Also, a high percentage of crowding is noteworthy.
Nearly one-third of the evaluated population would have a mandatory need for orthodontic treatment, if the DHC scores were used as the main criterion for such decisions. If the AC scores were used, the need would decrease to one-fifth of the sample. These results revealed the high percentage of need for orthodontic treatment in Turkey.

\section{REFERENCES}

1. Bentele MJ, Vig KW, Shanker S, Beck FM. Efficacy of training dental students in the index of orthodontic treatment need. Am J Orthod Dentofacial Orthop. 2002 Nov:122(5):456-62.

2. Brunelle JA, Bhat M, Lipton JA. Prevalence and distribution of selected occlusal characteristics in the US population, 1988-1991. J Dent Res. 1996 Feb;75 Spec No:706-13

3. Tschill P, Bacon W, Sonko A. Malocclusion in the deciduous dentition of Caucasian children. Eur J Orthod. 1997 Aug:19(4):361-7.

4. Thilander B, Pena L, Infante C, Parada SS, de Mayorga C. Prevalence of malocclusion and orthodontic treatment need in children and adolescents in Bogota, Colombia. An epidemiological study related to different stages of dental development. Eur J Orthod. 2001 Apr;23(2):153-67.

5. Tausche E, Luck O, Harzer W. Prevalence of malocclusions in the early mixed dentition and orthodontic treatment need. Eur J Orthod. 2004 Jun;26(3):237-44

6. Ciuffolo F, Manzoli L, D'Attilio M, Tecco S, Muratore F, Festa F, et al. Prevalence and distribution by gender of occlusal characteristics in a sample of Italian secondary school students: a cross-sectional study. Eur J Orthod. 2005 Dec;27(6):601-6. Epub 2005 Jul 11

7. Perillo L, Masucci C, Ferro F, Apicella D, Baccetti T. Prevalence of orthodontic treatment need in southern Italian schoolchildren. Eur J Orthod. 2010 Feb;32(1):49-53

8. Gelgör IE, Şişman Y, Malkoç S. Prevalence of congenital hypodontia in the permanent dentition. Turkiye Klinikleri J Dental Sci. 2005;11(2):43-8.

9. Evans R, Shaw W. Preliminary evaluation of an illustrated scale for rating dental attractiveness. Eur J Orthod. 1987 Nov:9(4):314-8.

10. Brook PH, Shaw WC. The development of an index of orthodontic treatment priority. Eur J Orthod. 1989 Aug;11(3):309-20.

11. Shaw WC, Richmond S, O'Brien KD, Brook P, Stephens CD. Quality control in orthodontics: indices of treatment need and treatment standards. Br Dent J. 1991 Feb 9;170(3):107-12

12. Cooper S, Mandall NA, DiBiase D, Shaw WC. The reliability of the index of orthodontic treatment need over time. J Orthod. 2000 Mar;27(1):47-53.

13. Josefsson E, Bjerklin K, Lindsten R. Malocclusion frequency in Swedish and immigrant adolescents: influence of origin on orthodontic treatment need. Eur J Orthod. 2007 Feb;29(1):79-87.

14. Chestnutt IG, Burden DJ, Steele JG, Pitts NB, Nuttall NM, Morris AJ. The orthodontic condition of children in the United Kingdom, 2003. Br Dent J. 2006 Jun;200(11):609-12.

15. Krey KF, Hirsch C. Frequency of orthodontic treatment in German children and adolescents: influence of age, gender, and socio-economic status. Eur J Orthod. 2012 Apr;34(2):152-7
16. Souames M, Bassigny F, Zenati N, Riordan PJ, Boy-Lefevre ML. Orthodontic treatment need in French schoolchildren: an epidemiological study using the Index of Orthodontic Treatment Need. Eur J Orthod. 2006 Dec:28(6):605-9.

17. Nobile CG, Pavia M, Fortunato L, Angelillo IF. Prevalence and factors related to malocclusion and orthodontic treatment need in children and adolescents in Italy. Eur J Public Health. 2007 Dec;17(6):637-41.

18. Gelgör IE, Karaman Al, Ercan E. Prevalence of malocclusion among adolescents in central Anatolia. Eur J Dent. 2007 Jul;1(3):125-31

19. Güray E, Ertas E, Orhan M, Doruk C. An epidemiologic survey using "Treatment Priority Index" (TPI) on primary school children in Konya. Türk Ortodonti Derg. 1994 Nov:7(2):195-200.

20. Ugur T, Ciger S, Aksoy A, Telli A. An epidemiological survey using the Treatment Priority Index (TPI). Eur J Orthod. 1998 Apr:20(2):189-93.

21. World Health Organization. International collaboration study of oral health outcomes (ICS II), document 2: oral data collection and examination criteria Geneva: WHO; 1989.

22. Silva RG, Kang DS. Prevalence of malocclusion among Latino adolescents. Am J Orthod Dentofacial Orthop. 2001 Mar;119(3):313-5.

23. Landis JR, Koch GG. The measurement of observer agreement for categorical data. Biometrics. 1977 Mar;33(1):159-74.

24. Haynes S. The prevalence of malocclusion in English children aged $11-12$ years Report of the congress. Eur Orthod Soc. 1970:89-98.

25. Foster TD, Day AJ. A survey of malocclusion and the need for orthodontic treatment in a Shropshire school population. Br J Orthod. 1974 Apr;1(3):73-8.

26. Lauc T. Orofacial analysis on the Adriatic islands: an epidemiological study of malocclusions on Hvar Island. Eur J Orthod. 2003 Jun;25(3):273-8.

27. McNamara JA Brudon WL. Orthodontics and dentofacial orthopedics. Ann Arbor: Needham Press; 2001

28. Goose DH TD, Winter FC. Malocclusion in school children of the West Midlands Br Dent J. 1957:102:174-8

29. Proffit WR, Fields HW Jr, Moray LJ. Prevalence of malocclusion and orthodontic treatment need in the United States: estimates from the NHANES III survey. Int J Adult Orthodon Orthognath Surg. 1998:13(2):97-106.

30. Otuyemi OD, Ogunyinka A, Dosumu O, Cons NC, Jenny J. Malocclusion and orthodontic treatment need of secondary school students in Nigeria according to the dental aesthetic index (DAI). Int Dent J. 1999 Aug:49(4):203-10 